\title{
Yüksek Riskli HPV Pozitif Sitolojik Sonuçların, Kolposkopik Biyopsi Sonuçları ile
} Karşılaştırılması

\author{
Comparison of Colposcopic Biopsy Results with High Risk HPV Positive Cytologic \\ Results
}

\author{
$\underline{\text { Talip KARACOR }}{ }^{1}$ (D) , Sibel SAK ${ }^{2}$ (D) , Mert Ulaş BARUT 2 (D), Nurullah PEKER ${ }^{3}$ (D), Muhammet Erdal SAK ${ }^{2}$ (D)
}

1 Adıyaman Üniversitesi Tıp Fakültesi, Kadın Hastalıkları ve Doğum Anabilim Dalı

2 Harran Üniversitesi Tıp Fakültesi, Kadın Hastalıkları ve Doğum Anabilim Dalı

3 Diyarbakır Kadın Doğum ve Çocuk Hastalıkları, Eğitim ve Araştırma Hastanesi

\section{Öz.}

Amaç: Yüksek risk HPV pozitif, normal veya anormal sitolojik bulgusu olan hastalarda kolposkopik biyopsi sonuçların değerlendirilmesi ve bu biyopsi sonuçları ile birliktelik gösteren yüksek risk HPV tiplerinin dağıımının belirlenmesi amaçlandı.

Materyal ve Metod: Ocak 2017 ve Eylül 2017 tarihleri arasında rutin jinekolojik kontrol veya herhangi bir jinekolojik şikayetle Harran Üniversitesi Kadın Hastalıkları ve Doğum Kliniğine başvuran hastalar ile gerçekleştirildi. Hastalar 20-30, 31- 40 ve 40 yaş üstü olmak üzere 3 gruba ayrıldı. Hastalardan papsmear ve eş zamanlı olarak serviks transformasyon zonundan ve servikal eksternal os'tan HPV taraması için sürüntü alındı ve yüksek risk HPV DNA varlığı araştııldı. Yüksek risk HPV pozitif normal veya anormal sitolojik bulgusu olan 84 hasta çalışmaya dahil edildi.

Bulgular: Yüksek risk HPV pozitifliği olan 84 hastanın smear sonuçları; \%61,9 inflamasyon, \%6 ASCUS, \%17,9 LGSIL, \%10,7 yüksek dereceli servikal intraepitelyal lezyon, \%1,2 atipik skuamoz hücreler-yüksek dereceli lezyonun ekarte edilemediği (ASC-H) ve \% 2.4 atrofi olarak raporlandı. Smear sonucu inflamasyon olan hastalarda en sık kolposkopik biyopsi tanısı CIN I $(\% 21,2)$, önemi bilinmeyen atipik skuamoz hücre olanlarda CIN II (\%40), düşük dereceli servikal intraepitelyal lezyon olanlarda, epitelyal hiperplazi $(\% 33,3)$ idi. Smear sonucu HSIL olan hastalarda \%44,4 CIN II ve CIN III, \%11,1 CIN I patolojik tanıları raporlandı. Skuamoz kanser tanıSI alan iki hastada HPV 16, bir hastada ise HPV 18 pozitifliği saptanırken serviks adenokanser tanısı alan iki hastanın birinde HPV 16, diğerinde ise HPV 18 tespit edildi.

Sonuç: Yüksek risk HPV pozitif olan hastalarda smear sonucundan bağımsız yapılan kolposkopik biyopsi ile displazik lezyonları saptama olasılığı artmaktadır. İleride daha kapsamlı çalışmalarla yüksek risk HPV taramasının tek başına smear testinin yerini alabileceğini düşünmekteyiz.

Anahtar kelimeler: HPV, Smear, Kolposkopi, Sevikal patoloji

\section{Abstract}

Background: The aim of the present study was to evaluate the pathologic results of colposcopic examination of patients with High Risk HPV (HR-HPV) who have normal or abnormal cytologic findings and to identify the distribution of HPV types with biopsy results.

Materials and Methods: The present study was performed between January 2017 and September 2017 in patients who attended to Harran University Obstetrics and Gynecology Clinic for routine gynecological control or any gynecological complaints. Patients were divided into 3 groups of 20-30, 31-40 and over 40 years old. Pap smear and swab samples were taken concurrently from cervical transformation zone and external cervical ostium and presence of high-risk HPV-DNA were searched. Eighty-four patients with HR-HPV who have normal or abnormal cytologic findings were included in the study.

Results: The smear results of 84 patients with HR-HPV positivity were reported as $61.9 \%$ inflammation, $6 \%$ ASCUS, $17.9 \%$ LSIL, $17.9 \%$ HSIL, $1.2 \%$ ASC-H and $2.4 \%$ atrophy. The most common colposcopic biopsy was CIN I (21. 2\%) in patients with inflammatory cytological result, CIN II (40\%) in patients with ASCUS and epithelial hyperplasia (33. 3\%) in patients with LSIL. Patients with HSIL cytological result had $44.4 \%$ both CIN II and CIN III, 11.1\% CIN I pathologic diagnoses. HPV 16 was detected in two patients with squamous cancer and HPV 18 was detected in one patient with squamous cancer. HPV 16 and HPV 18 were detected in two patients who had a cervical adenocarcinoma diagnosis.

Conclusion: In HR-HPV positive patients, colposcopic biopsy independent of smear results is likely to detect the presence of dysplasic lesions. With more in the future, we think HR-HPV screening alone may take place of the smear test.

Key words: HPV, Smear, Colposcopy, Cervical pathology

\section{Sorumlu Yazar I \\ Corresponding Author}

Dr. Talip KARAÇOR,

Adıyaman Üniversitesi

Tıp Fakültesi

Kadın Hastalıkları ve Doğum AnaBilim Dalı,

Yunus Emre Mahallesi, Atatürk Bulvarı, Kadın Doğum ve Çocuk Hastalıkları Hastanesi, 02100, Adıyaman/Türkiye.

Tel : +90 5326809088 ,

e mail:talipkaracor@gmail.com

Geliş tarihi / Received:

21.11.2019

Kabul tarihi / Accepted: 16.12.2019

DOI: 10.35440/hutfd.649689 


\section{Giriş}

Serviks kanseri kadınlarda en sık görülen kanserler arasında üçüncü sırada yer almakta ve kadınlarda kansere bağlı ölüm nedenleri arasında ikinci sırayı almaktadır (1). Gelişmiş ülkelerde servikal kanser tarama yöntemlerinin gelişmesi ve tarama sıkığının artmasıyla serviks kanserinin görülme sıkığı ve mortalite oranları azalmıştır. Serviks kanserini tarama da en sık kullanılan yöntem Papanicolaou (Pap) smear testidir. Tek bir pap test servikal prekanseröz lezyon ve servikal kanseri saptamada \%50-60 duyarıdır ve etkinlik için testin sık tekrarı gereklidir (2-4). Amerikan kanser cemiyeti (ACS ) 2002 'de yayınladığı kılavuzda primer taramanın smear testi olması gerektiğini vurgularken 2012 ' de yayınlanan kılavuzda sitolojiye ek olarak servikal kanser gelişiminde primer rol oynayan Human Papilloma Virus (HPV) tiplemesinin yapılmasını da önermektedir (CO test) (5-7). HPV testi ile tek sitoloji taramasinda atlanan lezyonların \% 25-50'si saptanabilmektedir (8). HPV testinin kullanımı, servikal prekanseröz lezyon ve servikal kanserlerin teshis oranını artırmakta ve servikal kanser tarama sıklığını azaltmaktadır.

Anormal smear bulgusu veya yüksek riskli HPV varlığında kesin patolojik sonucun elde edilmesinde, lezyonun boyut ve lokalizasyonunun saptanmasında aynızamanda teropatik amaçlı kolposkopik inceleme yapılmaktadır (9).

Bu çalışmada amacımız smear sitolojik incelemesıyle birlikte HPV taraması yapılan ve yüksek riskli HPV pozitifliği saptanan hastalarda kolposkopi eşliğinde alınan servikal biyopsi ile sitoloji sonuçları karşılaştırmak ve servikal biyopsi sonucuna eşlik eden HPV tiplerini belirlemektir.

\section{Materyal ve Metod}

Bu çalışma Ocak 2017 ve Eylül 2017 tarihleri arasında Harran Üniversitesi Kadın Hastalıkları ve Doğum Kliniğinde, yerel etik kurul onayı alındıktan sonra retrospektif olarak gerçekleştirildi. Hastalar Kadın Hastalıkları ve Doğum polikliniğine rutin jinekolojik kontrol veya herhangi bir jinekolojik şikayetle başvuran hastalardan seçildi. Hastaların demografik verileri ve klinik bilgileri hasta dosyaları ve dijital veri tabanları incelenerek elde edildi. Hastalar 20-30 yaş, 31-40 yaş ve 40 yaş üstü olmak üzre 3 gruba ayrıldı Servikal sitoloji sonuçları inflamasyon, önemi bilinmeyen atipik skuamoz hücreler (ASCUS), düşük dereceli servikal intraepitelyal lezyon (LGSIL), yüksek dereceli servikal intraepitelyal lezyon (HGSIL), atipik skuamoz hücreler, yüksek dereceli lezyonun ekarte edilemediği (ASC-H), atrofi olan aynı zamanda bu bulgularla HR-HPV birlikteliği olan 84 hasta çalışmaya dahil edildi. Smear alınan hastaların foliküler dönemde olması, testten 3 gün önce ilişki, vajinal duş veya vajinal fitil, krem, jel gibi herhangi bir uygulama olmamasına dikkat edildi. Çok yoğun akıntısı olan hastalar tedavi sonrası smear testi için çağrıldı. Hastalardan alınan servikal sürüntü örnekleri Bethesda sistemine göre değerlendirildi ve raporlandı.
Endoservikal hücrelerin varlğı servikal yaymanın yeterliliği için kriter alındı. HPV tiplendirme analizleri ise cobas ${ }^{\circledR}$ HPV tests (Roche) ile yapıldı. Bu test polimeraz zincir reaksyonu ve nükleik asit hibridizasyon yöntemiyle yüksek riskli $14 \mathrm{HPV}$ tipini $(16,18,31,33,35,39,45,51,52,56$, $58,59,66,68)$ belirleyebilme kapasitesine sahipti. Smear sonuçlarından bağımsız yüksek riskli HPV saptanan hastalara kolposkopi yapıldı. Serviks serum fizyololojik ile yıkandıktan sonra atipik damarlanma açısından yeşil filtre ile incelendi. Sonrasında \% 5 asetik asit ile aseto white alan varlığı araştırıldı. Lugol solusyonu ile de serviks boyanarak lugol tutulumu olmayan alanlar tespit edildi. Patolojil bulguların olduğu alanlardan punch biyopsiler alındı. Patolojik görünüm tespit edilemeyen hastalarda ise 4 kadran (saat 12, 3, 6, 9 hizasından) kontrol biyopsisi alındı.

Veriler SPSS 20 programi kullanılarak analiz edildi. Nominal değişkenler olgu sayısıve yüzde olarak belirtildi. Tanımlayıcı değişkenler ortalama \pm standart sapma olarak belirtildi.

\section{Bulgular}

Çalışmaya dahil edilen hastaların yaş ortalaması 44 . $05 \pm 10.1$ (22-75) idi. Ortalama gebelik sayısı ise 4. 92 \pm 2.1 (1-12) idi. Kadınların 1'i (\%1. 2) primipar, 59'u (70. 3) multipar, 24'ü (28.5) ise grand multipardı. Yükse risk HPV pozitifligi olan 84 hastanın smear sonuçlarl; \% 61.9 inflamasyon, \%6 ASCUS, \% 17.9 LSIL, \%10.7 HSIL, \%1.2 ASC$\mathrm{H}$ ve \% 2.4 atrofi olarak raporlandı. Smear sonucu inflamasyon olan hastalarda en sık kolposkopik biyopsi tanısı CIN I (\% 21.2), ASCUS olanlarda CIN II (\%40), LSIL olanlarda epitelyal hiperplazi (\%33.3) idi. Smear sonucu HSI L olan hastalarda \% 44.4 CIN II VE CIN III, \% 11.1 CIN I biyopsi sonucları saptandı. Sadece bir hastanın smear sonucu ASC H olarak raporlandı, biyopsi sonucunun ise inflamasyon olduğu görüldü. Kolposkopik biyopsi sonuçlarına göre üç hastada servikal skuamoz kanser ve iki hastada servikal adenokanser tespit edildi. Skuamoz kanser tanılı hastaların ikisinde LSIL, birinde HSIL sitoloji sonucu mevcuttu. Servikal adenokanser tanısı alan her iki hastanında smear sonucu HSIL idi (Tablo 1). Smear sonuçları ile kolpaskopik biyopsi sonuçlarının dağılımı Resim 1 de gösterilmiştir.

Yüksek risk HPV tiplemesi positıf olan hastaların kolposkopik biyopsi sonuçları değerlendirildiğinde HPV 16 ' nın en sIk CIN II (\%23. 8) ile HPV 18 in ise CIN III (\%23.1) ve CIN II (\%23.1) ile birliktelik göstediği izlendi. Yüksek risk HPV 30 tipleri sıklıkla CIN I' e (\%29.1) ve yüksek risk HPV 50 tipleri kronik servisite (\%39.1) eşlik etmekteydi (Tablo 2), (Resim 2). Skuamoz kanser tanısı alan iki hastada HPV 16, bir hastada ise HPV 18 positifliği saptanırken serviks adena kanser tanısı alan 2 hastanın birinde HPV 16, birinde ise HPV 18 tespit edildi. HPV örneklemesinde HRHPV 16 tipi en sık saptanan (21(\%25)) HPV oldu (Tablo 2). 
Tablo 1. Smear sonuçları ile biyopsi sonuçlarının karşılaştırıması.

\begin{tabular}{|c|c|c|c|c|c|c|c|c|c|c|}
\hline $\begin{array}{c}\text { Smear } \\
\text { Sonuçları }\end{array}$ & $\begin{array}{c}\text { İflamasyon } \\
\mathrm{n}(\%)\end{array}$ & $\begin{array}{l}\text { CIN I } \\
\text { n (\%) }\end{array}$ & $\begin{array}{l}\text { CIN2 } \\
\mathrm{n}(\%\end{array}$ & $\begin{array}{l}\text { CIN } 3 \\
\text { n (\%) }\end{array}$ & $\begin{array}{c}\text { Kronik } \\
\text { servisit } n(\%)\end{array}$ & $\begin{array}{l}\text { Epitelyal hiper- } \\
\text { plazi } \mathrm{n}(\%)\end{array}$ & $\begin{array}{c}\text { Servikal polip } \\
\mathrm{n}(\%)\end{array}$ & $\begin{array}{c}\text { Skuamoz kanser } \\
\mathrm{n}(\%)\end{array}$ & $\begin{array}{c}\text { Adeno } \\
\text { karsinom } \\
(\%)\end{array}$ & $\begin{array}{cc} & \text { Total } \\
n & (\%)\end{array}$ \\
\hline İnflamasyon & $10(19.2)$ & $\begin{array}{l}11 \\
(21.2)\end{array}$ & $5(9.6)$ & $2(3.8)$ & $12(23.1)$ & $7(13.5)$ & $5(9.6)$ & - & - & $52(61.9)$ \\
\hline ASCUS & $1(20.0)$ & $1(20.0)$ & $2(40.0)$ & _ & _ & $1(20.0)$ & _ & _ & _ & $5(6)$ \\
\hline LSIL & $4(26.7)$ & $2(13.3)$ & _- & - & $2(13.3)$ & $5(33.3)$ & - & $2(13.3)$ & _- & $15(17.9)$ \\
\hline HSIL & - & 1 (11.1) & $2(22.2)$ & $2(22.2)$ & _ & 1 (11.1) & - & 1 (11.1) & $2(22.2)$ & $9(10.7)$ \\
\hline $\mathrm{ASCH}$ & $1(100)$ & - & - & - & - & - & - & - & - & $1(1.2)$ \\
\hline Atrofi & - & - & - & - & $2(100)$ & - & - & - & - & $2(2.4)$ \\
\hline
\end{tabular}

Kısaltmalar: ASCUS: Atipik skuamoz hücreler, önemi bilinmeyen; ASC-H: Atipik skuamoz hücreler, yüksek derceli lezyonun ekarte edilemediği; LSIL: Düşük dereceli servikal intraepitelyal lezyon; HSIL; Yüksek dereceli servikal intraepitelyal lezyon; ASC H: Atipik skuamoz hücreler, yüksek derceli lezyonun ekarte edilemediği; CIN: Servikal intraepitelyal neoplazi.

Yaş aralıklarına göre kolposkopik biyopsi sonuçları değerlendirildiğinde 20-30 yaş grubu kadınlarda inflamasyon (\%100), 31-40 yaş kadınlarda prekanseröz lezyonlar olan CIN I (\%24.2) VE CIN II (\%15.2) ve CIN III (\%6) 'ün sıklıkla izlendiği görüldü. Serviks kanserlerinin tümü 40 yaş üstü kadinlarda tanı aldı (Tablo 3.)

Tablo 2. Smear sonuçlarının ve biyopsi sonuçlarının karşılaştırilması.

\begin{tabular}{|l|l|l|l|l|l|l|l|l|l|l|}
\hline $\begin{array}{l}\text { HPV } \\
16\end{array}$ & $\begin{array}{l}2 \\
(9.5)\end{array}$ & $1(4.8)$ & $\begin{array}{l}5 \\
(23.8)\end{array}$ & $3(14.3)$ & $3(14.3)$ & $\begin{array}{l}3 \\
(14.3)\end{array}$ & $\begin{array}{l}1 \\
(4.8)\end{array}$ & $\begin{array}{l}2 \\
(9.5)\end{array}$ & $\begin{array}{l}1 \\
(4.8)\end{array}$ & $21(25)$ \\
\hline $\begin{array}{l}\text { HPV } \\
18\end{array}$ & $\begin{array}{l}2 \\
(15.4)\end{array}$ & $3(23.1)$ & $3(23.1)$ & $1(7.7)$ & - & $1(7.7)$ & $1(7.7)$ & $\begin{array}{l}1 \\
(7.7)\end{array}$ & $1(7.7)$ & $13(15.5)$ \\
\hline $\begin{array}{l}\text { HPV } \\
30\end{array}$ & $\begin{array}{l}5 \\
(20.8)\end{array}$ & $7(29.1)$ & $1(4.1)$ & - & - & $6(25)$ & $\begin{array}{l}2 \\
(8.3)\end{array}$ & - & - & $24(28.5)$ \\
\hline $\begin{array}{l}\text { HPV } \\
45\end{array}$ & - & $1(50)$ & - & - & $1(50)$ & - & - & - & - & $2(2.3)$ \\
\hline $\begin{array}{l}\text { HPV } \\
50\end{array}$ & $\begin{array}{l}7 \\
(30.4)\end{array}$ & $2(8.6)$ & - & - & $\begin{array}{l}9 \\
(39.1)\end{array}$ & $\begin{array}{l}4 \\
(17.3)\end{array}$ & $\begin{array}{l}1 \\
(4.3)\end{array}$ & - & - & $23(27.3)$ \\
\hline $\begin{array}{l}\text { HPV } \\
66\end{array}$ & - & $1(100)$ & - & - & - & - & - & - & - & $1(1.1)$ \\
\hline
\end{tabular}

\section{Tartışma}

Serviks kanseri, displazi zemininde gelişmekte ve displazik lezyonların kansere dönüşme süresi uzun zaman almaktadır. Bu özelliklerden dolayı serviks kanseri önlenebilir bir kanserdir. Serviks kanserinin önlenebilir olması tarama yöntemlerini ön plana çıkarmaktadır. Mevcut tarama yöntemleri ile asemptomatik olan serviks preinvaziv lezyonlar saptanabilmekte ve gelişmiş ülkelerde düzenli olarak uygulanması mortalite oranlarını \% 60-80 oranında azaltı̆̆ı bildirilmektedir (10). Servikal sitoloji taramada en sık kullanılan testtir ancak 2012 ACS'nin yayınladığı güncel kılavuzda sitoloji taramasına HPV DNA tiplendirilmesinin eklenmeside önerilmektedir (6). HPV testinin eklenmesi ile PAP testinin uygulanma sıklığı ve sık tekrarlanan pap testine bağı ıastalarda morbidite artışı azalmıştır. Kendi kendine regrese olma ihtimali yüksekolan CIN II gibi lezyonların LEEP/Konizasyonla gereksiz tedavisi engellendiği, bu tedavilere bağlı perinatal morbiditede (preterm eylem, PROM gibi ) oranlar nın düştüğü bildirilmektedir $(11,12)$.
Türkiye'de sitolojik testlerde ASCUS görülme sıklığı $\% 1.07$, LSIL \%0.3, HSIL \% 0.17 dir (13). Biz yüksek risk HPV pozitif olan hasta grubunda yaptığımız sitolojik incelemede $\% 61.9$ inflamasyon, $\% 6$ ASCUS, $\% 17.9$ LSIL, $\% 9$ HSIL ve \%1.2 ASC-H saptadık. Bu oranların Türkiye'deki istatistiklere göre daha yüsek olması çalışmaya dahil ediIen hastalarda aynı zamanda yüksek risk HPV birlikteliği olmasına bağlandı.

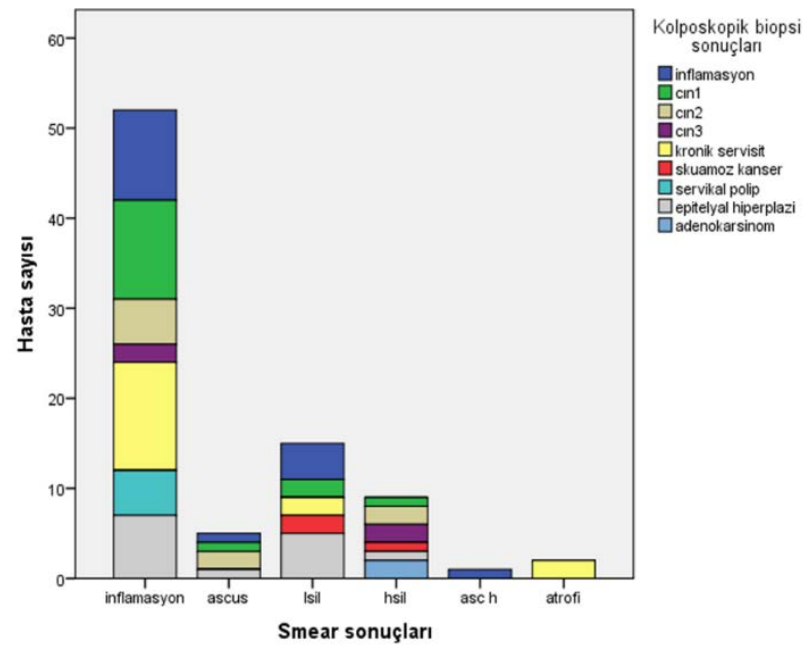

Şekil 1. Smear sonuçlarına göre kolposkopik biyopsi sonuçlarının dağılımı.

Smear testinin sensivitesi \% 30-87 arasında değişmektedir. Sitoloji test sensivite oranını $\% 30$ a kadar düşebilmesi nedeniyle sitolojik anormal bulguların kolposkopik biyopsi ile de değerlendirimesi gerekmektedir $(2,14)$. Servikal sitoıji ve biyopsi tanıları arasında yapılan sitohistolojik korelasyon çalışmalarında uyumsuzluk olabileceğinden uyumsuzluk nedenlerinin saptanması gerekmektedir. Uyumsuzluk nedeni sitolojik örnekleme, sitolojik örneği tespit ve hazırlama ya da mikroskopik değerlendirme sürecine bağlı gelişebilmektedir. Bu nedenle klinikler arası optimal kalite kontrol mekanizmasının oluşturulması önemlidir (15, 16). 
Tablo 3.Yaş aralıklarına göre kolposkopik biyopsi sonuçlarının karşılaştırılması

\begin{tabular}{|c|c|c|c|c|c|c|c|c|c|c|}
\hline & $\begin{array}{l}\text { İnflamasyon } \\
\mathrm{n}(\%)\end{array}$ & $\begin{array}{l}\text { CIN } 1 \\
\mathrm{n}(\%) \\
\end{array}$ & $\begin{array}{l}\text { CIN } 2 \\
\mathrm{n}(\%) \\
\end{array}$ & $\begin{array}{l}\text { CIN3 } \\
\mathrm{n}(\%) \\
\end{array}$ & $\begin{array}{l}\text { Kronik } \\
\text { servisit } \\
\mathrm{n}(\%) \\
\end{array}$ & $\begin{array}{l}\text { Epitelyal } \\
\text { hiperplazi } \\
\mathrm{n}(\%)\end{array}$ & $\begin{array}{l}\text { Servikal polip } \\
\text { n (\%) }\end{array}$ & $\begin{array}{l}\text { Skuamoz } \\
\text { kanser } \\
\mathrm{n}(\%)\end{array}$ & $\begin{array}{l}\text { Adeno } \\
\text { Karsinom } \\
\mathrm{n}(\%)\end{array}$ & $\begin{array}{l}\text { Total } \\
\text { n (\%) }\end{array}$ \\
\hline $\begin{array}{l}20-30 \\
\text { (yaş) }\end{array}$ & $3(100)$ & - & - & - & - & - & - & - & - & $3(100)$ \\
\hline $\begin{array}{l}31-40 \\
\text { (yş) }\end{array}$ & $7(21.2)$ & $8(24.2)$ & $5(15.1)$ & $2(6)$ & $4(12.1)$ & $5(15.2)$ & $2(6.1)$ & - & - & $33(100)$ \\
\hline $\begin{array}{l}>40 \\
\text { (yaş) }\end{array}$ & $9(18.8)$ & $7(14.6)$ & $4(8.3)$ & $2(4.2)$ & $11(22.9)$ & $8(16.7)$ & $2(4.2)$ & $3(6.2)$ & $2(4.2)$ & $48(100)$ \\
\hline
\end{tabular}

Smear sonucu inflamasyon olarak rapor edilen HR-HPV' li hastalarda biyopsi sonuçları \%21.2 CIN I, \% 9.6 CIN II ve \% 3.8 CIN III şeklinde idi. Sitoloji inflamasyon olup biyopsi sonucu CIN III olan hastalarin birinde HPV 16 diğerinde HPV 18 positifliği mevcuttu. Bu sonuçlar incelendiğinde; tarama programlarının asıl hedefi CIN III lezyonlarını saptamak olduğundan co-test yapılan kadınlarda litaratürle uyumlu olarak normal sitolojik bulgu ile HPV 16 ve 18 birlikteliği olması kolposkopik biyopsi yapılmasi gerekliliğini düşündürmektedir (6).

Amerikan Servikal Patolojiler ve Kolposkopi Derneği (ASCCP, 2015), sitolojisi ASCUS veya daha ileri dizplazik lezyon olan hastalarda HR-HPV varlığında doğrudan kolposkopik incelemeyi önermiştir.

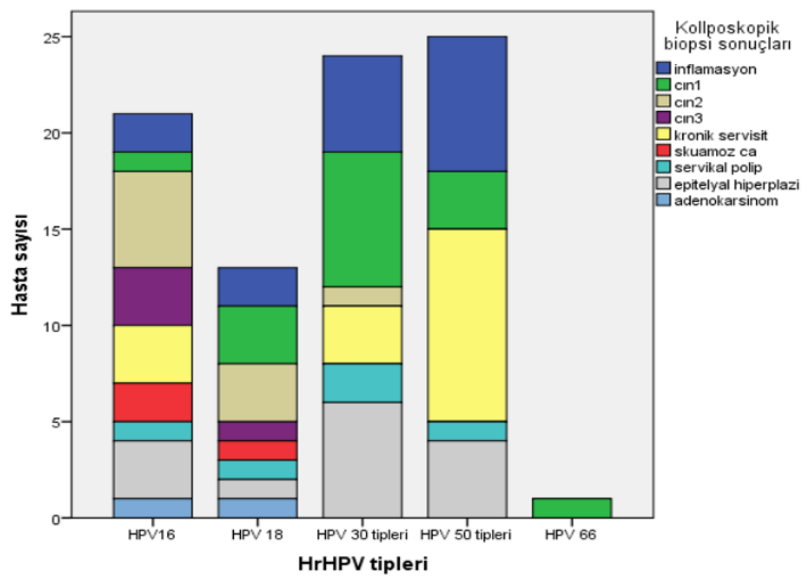

Şekil 2. Patolojik tanılara göre HPV dağııımı.

Sitolojisi ASCUS olan HR-HPV' li hastalarda \% 20 CIN I ve $\% 40$ CIN II biyopsi sonuçları elde edildi. Biyopsi sonucu CIN I olan bir hastada HPV 16, CIN II olan bir hastada HPV 16, bir hastada HPV 35 birlikteliği vardi. Her ne kadar CIN II lezyonlarının \% 40' । kendiliğinden regrese olsada kalan kısmı persiste veya invaze olabileceğinden bu lezyonun tespitide takip sıklığı ve tedavi açısından önem taşımakta$\operatorname{dir}(17)$.

Özellikle serviks adenokarsinomların tespitinde smear yetersiz kalabilmektedir. Pap smearın atladığı adenokarsinom vakalarını HPV ile saptamak mümkündr. Bu hastalarda HPV saptama oranı \%93 tür (18). Katki HA ve arkadaşları beş yıl içinde gelişen adenokarsinom olguların \%63 ünün HPV+PAP negatif hastalar olduğunu saptamıştır (19). Çalışmamızda smear sonucu LSIL olan hastaları \% 13.3' üne skuamoz kanser, HSIL olanların \% 11.1' ine skuamoz kanser, \% 22.2'sine de adenokarsinom tanıları konuldu. Kanser tanısı alan hastalarda HPV 16 veya HPV 18 pozitifliği bulunmaktaydı. Çalışmamızdaki bu sonuçlar ASCCP (2015) önerdiği gibi ASCUS ve daha ağır dizplazik lezyonlarla HR-HPV birlikteliği olan hastalarda kolposkpi yapılması görüşünü desteklemektedir.

HPV genotiplerinin araştıııldı̆ı çalışmalar incelendiğinde; Ergünay ve ark. 14 ASCUS, 3 ASC-H, 5 HSIL, ve 7 LSIL olgusunu dahil ettikleri çalışmalarında en sık karşılaştıkları HPV tipinin \%50 ile HPV 16 olduğunu, HPV 18'in \%10.7 ile ikinci, HPV 53'ün ise üçüncü sırada olduğunu bildirmişlerdir (20). Bell ve ark. yüksek ve düşük riskli HPV tiplerini araştırdıkları, normal servikal sitolojiye sahip kadınlarda, smear sonucu ASCUS ve HSIL olan olgularda en sIk rastlanılan HPV tipinin HPV 16, LSIL grubunda ise HPV 59, olduğunu bildirmişlerdir (21).

Normal ve anormal sitolojik sonuçları kapsayan HPV dağıIımını araştıran çalışmamızda litaratürle uyumlu olarak en sık saptanan HPV tipinin HPV 16 (\% 25) ve HPV 18 (\%15.5) olduğu bulundu. HPV 16, HPV 18 ve HPV 30 (31, $33,35,39)$ dışındaki tipler ile prekanseöz lezyon ve servilks kanseri birlikteliği gösterilemedi.

Serviks kanseri progresyonunu araştıran çalışmalarda HPV enfeksiyonu ve inflamasyonun 20' li yaşlarda; bir on yıl sonra 30' lu yaşlarda prekanseröz lezyonların ve ondan bir 10 yll sonra 40' I yaşlarda invazif serviks kanserinin peak yaptığı belirtilmiştir $(22,23)$. Bizde çalışmamızda diğer çalışmalar gibi HR-HPV' li hastalarda 20-30 yaş aralığında inflamasyonun, 30-40 yaş araliğinda prekanseröz lezyonların, 40 yaş üstü kadınlarda serviks kanserinin baskın olduğunu saptadık. Serviks kanserine progresyonun çok uzun yillar olduğunu belirten bu veri; düzenli servikal tarama yaptıran kadınlarda servikal kanser tanısı atlanmasının nerdeyse imkansız olduğunu göstermektedir. Çalışmanın tek merkezli olması ve hasta sayısının kısıtı olmasını; araştırmanın sonuçlarını etkileyen ve sınırlandıran en önemli iki faktör olarak düşünmekteyiz. Sonuç olarak HPV 16 ve HPV 18 pozitif pap smear negatif olgularda ve HRHPV pozitif ASCUS veya daha ağır dizplazik lezyonlarda kolposkopik inceleme preinvaziv ve invaziv serviks kanserini tespit etme olasılığını artırmaktadır. Ancak ülkemizde 
ve Dünyada HPV enfeksiyonlarının epidemiyolojisinin, HPV tip dağılımının olması ve eşlik ettiği patolojik anomalilerin saptanması için daha fazla sayıda örneğin incelendiği kapsamlı çalışmalarla tek başına yüksek risk HR-HPV taramasının smear testinin yerini alabileceğini düşünmekteyiz.

\section{Açıklama}

Yazarlar makalenin yazılmasında ve basılmasında her hangi bir çıkar çatışması olmadığını beyan eder.

\section{Kaynaklar}

1. Peto J, Gilham C, Fletcher O, Matthews FE. The cervical cancer epidemic that screening has prevented in the UK. The Lancet 2004;364(9430):249-256.

2. Nanda K, McCrory DC, Myers ER, Bastian LA, Hasselblad V, Hickey JD ve ark. Accuracy of the papanicolaou test in screening for and follow-up of cervical cytologic abnormalities a systematic review. Annals of internal medicine 2000;132(10):810-819.

3. Meijer C, Helmerhorst TJ, Rozendaal L, Van der Linden J, Voorhorst $F$, Walboomers J. HPV typing and testing in gynaecological pathology: has the time come? Histopathology 1998;33(1):83-86.

4. Lizard G, Roignot $P$, Brunet-Lecomte $P$, Chardonnet $Y$. Morphological analysis of in situ hybridization signals in cervical intraepithelial neoplasia containing human papillomavirus type 16 or 18: relationship with histological grade and DNA content. Cytometry 1998;34(4):180-186.

5. Saslow D, Runowicz CD, Solomon D, Moscicki AB, Smith RA, Eyre $\mathrm{HJ}$ ve ark. American Cancer Society guideline for the early detection of cervical neoplasia and cancer. CA: a cancer journal for clinicians 2002;52(6):342-362.

6. Saslow D, Solomon D, Lawson HW, Killackey M, Kulasingam SL, Cain J ve ark. American Cancer Society, American Society for Colposcopy and Cervical Pathology, and American Society for Clinical Pathology screening guidelines for the prevention and early detection of cervical cancer. CA: a cancer journal for clinicians 2012;62(3):147-172.

7. Berkowitz RP. 2012 updated consensus guidelines for the management of abnormal cervical cancer screening tests and cancer precursors. Obstetrics \& Gynecology 2013;122(2, PART 1):393.

8. Rodríguez AC, Schiffman M, Herrero R, Wacholder S, Hildesheim A, Castle PE ve ark. Rapid clearance of human papillomavirus and implications for clinical focus on persistent infections. Journal of the National Cancer Institute 2008;100(7):513-517.

9. Benedet J, Matisic J, Bertrand M. An analysis of 84, 244 patients from the British Columbia cytology-colposcopy program. Gynecologic oncology 2004;92(1):127-134.

10. Valdespino VM, Valdespino VE. Cervical cancer screening: state of the art. Current Opinion in Obstetrics and Gynecology 2006;18(1):3540.

11. Kyrgiou M, Koliopoulos G, Martin-Hirsch P, Arbyn M, Prendiville W, Paraskevaidis E. Obstetric outcomes after conservative treatment for intraepithelial or early invasive cervical lesions: systematic review and meta-analysis. The Lancet 2006;367(9509):489-498.

12. Arbyn M, Kyrgiou M, Simoens C, Raifu A, Koliopoulos G, MartinHirsch $P$ ve ark. Perinatal mortality and other severe adverse pregnancy outcomes associated with treatment of cervical intraepithelial neoplasia: meta-analysis. Bmj 2008;337:a1284.

13. Cancer TC, Group CCR. Prevalence of cervical cytological abnormalities in Turkey. International Journal of Gynecology \& Obstetrics 2009;106(3):206-209.

14. Keskin HL, Seçen EI, Taş EE, Kaya S, Avşar AF. Servikal smear sitolojisi ile kolposkopi eşliğinde servikal biyopsi korelasyonu. Türk Jinekolojik Onkoloji Dergisi 2011;3:71-75.

15. Mete Ö, Yavuz E, Tuzlalı S, İlhan R, Özlük Y, Topuz S ve ark.
Kolposkopik biyopsi yapılan 112 hastanın retrospektif incelemesi: Sitolojik bulguların histoloji ile karşılaştırıması. Turk Patoloji Derg 2007;23:33-37.

16. Davey DD, Austin RM, Birdsong G, Buck HW, Cox JT, Darragh TM ve ark. ASCCP Patient Management Guidelines* Pap Test Specimen Adequacy and Quality Indicators. American journal of clinical pathology 2002;118(5):714-718.

17. Castle PE, Schiffman M, Wheeler CM, Solomon D. Evidence for frequent regression of cervical intraepithelial neoplasia-grade 2. Obstetrics and gynecology 2009;113(1):18.

18. Andersson S, Wallin K, Hellström A, Morrison L, Hjerpe A, Auer $\mathrm{G}$ ve ark. Frequent gain of the human telomerase gene TERC at $3 q 26$ in cervical adenocarcinomas. British journal of cancer 2006;95(3):331338.

19. Gage JC, Sadorra M, LaMere BJ, Kail R, Aldrich C, Kinney W ve ark. A comparison of the cobas $®$ HPV test with Hybrid Capture 2 and Linear Array HPV DNA tests. Journal of clinical microbiology 2011:JCM. 05989-05911.

20. Ergünay K, Misirlioğlu M, Firat P, Tuncer Zs, Tuncer S, Ustaçelebi Ş. Sitolojik Olarak Anomali Saptanan Serviks Örneklerinde Insan Papilloma Virus Dna'sinin Araştirimasi Ve Virusun Tiplendirilmesi. Mikrobiyol Bült 2007; 41: 219-226

21. Bell MC, Schmidt-Grimminger D, Patrick S, Ryschon T, Linz L, Chauhan SC. There is a high prevalence of human papillomavirus infection in American Indian women of the Northern Plains. Gynecologic oncology 2007;107(2):236-241.

22. Wentzensen N, Schiffman M, Dunn T, Zuna RE, Gold MA, Allen RA ve ark. Multiple human papillomavirus genotype infections in cervical cancer progression in the study to understand cervical cancer early endpoints and determinants. International journal of cancer 2009;125(9):2151-2158.

23.Bülbül M, Dilbaz B, Türk BA, Hatipoğlu F, Boyar E. Human Papilloma Virus Genotype Distribution in Women with Cervical Intraepithelial Neoplasia. Journal of Clinical Obstetrics \& Gynecology. 2018;28(3):11220. 